\title{
Peer Pressure, Incentives, and Gender: An Experimental Analysis of Motivation in the Workplace*
}

\author{
Charles Bellemare $^{\dagger} \quad$ Patrick Lepage $\quad$ Bruce S. Shearer ${ }^{\S}$ \\ January 29, 2007
}

\begin{abstract}
We present results from a real-effort experiment comparing the productivity of workers under fixed wages and piece rates. Workers working under both payment systems were exposed to different degrees of peer pressure in the form of private information about the productivity of their peers. We have three main results. First, under fixed wages, we find a significant inverted $U$ relationship between peer pressure intensity and the productivity of men. We argue that this relationship is consistent with theories of self-assessment and motivation. Second, we find no significant effect of peer pressure on productivity of women paid a fixed wage. Finally, we find no significant effect of peer pressure intensity on productivity of men or women when workers are paid a piece rate.
\end{abstract}

JEL Codes:

Keywords: Peer pressure, fixed wages, piece rates, productivity.

${ }^{*}$ Research Support from the Social Sciences and Humanities Council of Canada (SSHRC) is gratefully acknowledged.

${ }^{\dagger}$ Département déconomique, Université Laval, CIRPÉE, email: cbellemare@ecn.ulaval.ca.

‡Département déconomique, Université Laval, email: plepage@ecn.ulaval.ca.

§Département déconomique, Université Laval, CIRPÉE, email: bshe@ecn.ulaval.ca. 


\section{Introduction}

The economic study of personnel policies and work-place productivity has traditionally concentrated on monetary incentive mechanisms. Theorists have studied the ability of piece-rate contracts (eg. Stiglitz, 1975), tournaments (eg. Lazear and Rosen, 1981), and termination contracts (eg. MacLeod and Malcomson, 1989) to induce productive behaviour on the part of workers. These mechanisms offer extrinsic motivation; they induce productive behaviour through direct (or indirect) monetary rewards and punishments. ${ }^{1}$ Recently, however, economists have become increasingly interested in psychological notion of intrinsic motivation. Broadly speaking, this refers to motivation to perform a task that is independent of any direct monetary reward.

The study of intrinsic motivation has been both theoretical (Kandel and Lazear (1992), Bénabou and Tirole (2003)) and empirical (Deci, 1975). Experiments have proven to be particularly useful for empirical work in this area, allowing researchers to exogenously vary elements that would be difficult to observe in a real firm. One specific element of intrinsic motivation of recent interest to empirical researchers concerns peer pressure (Falk and Ichino (2006)). By making publicly available information about worker productivity, a firm can hope to raise the intrinsic motivation and, hence, the productivity of its workers without having to relate pay to individual or group productivity.

In this paper, we use experimental methods to analyse the effects of peer pressure on worker performance. During the experiment, male and female workers were paid to enter data on computer terminals. Performance was measured on the basis of the amount of data entered (controlling for quality). The experiment was completed in four treatments, varying the compensation system and peer pressure. Workers in the first and second treatments were paid, respectively, under fixed wages and piece rates, both in the absence of peer pressure. Workers in the third and fourth treatments were paid, respectively, under fixed wages and piece rates and were exposed to peer pressure. Peer pressure was generated by providing each worker with private information about the realized productivity of another worker in a past experimental session. Since productivity varies across individuals, different workers were exposed

\footnotetext{
${ }^{1}$ There is now a good deal of evidence showing that workers do respond to monetary incentives; see Paarsch and Shearer $(1999,2000)$ and Lazear (2000) for studies using field data and Shearer (2004) for a field experiment.
} 
to differing intensities of pressure. This design ensures that peer pressure is heterogeneously and exogenously distributed across subjects. This allows estimation of the effect of peer pressure intensity on productivity under both payment systems.

We use the data arising from the experiment to consider three issues related to the effectiveness of peer pressure. First, we analyze whether peer pressure is equally as effective as a motivational tool when workers are paid piece rates as when they are paid fixed wages. Recent evidence suggests that peer pressure can increase productivity when workers are paid a fixed wage (Falk and Ichino (2006)). However, evidence also suggests that extrinsic motivation crowds out intrinsic motivation (see Frey and Jegen (2001)). One explanation is that piece rates and fixed wages imply differing levels of extrinsic motivation, observed productivity under a piece rate may signal extrinsic rather than intrinsic motivation, leading to differing responses on the part of workers. Alternatively, if the marginal cost of effort is increasing, high effort levels associated with monetary incentives will imply lower responses to (and the crowding out of) intrinsic motivation.

Second, we empirically measure the effect of peer pressure intensity on the productivity of workers under fixed wages and piece rates. In Falk and Ichino (2006), peer pressure was generated by having pairs of subjects work simultaneously and together. Thus peer pressure was determined endogenously and implicitly. Our experiment, by posting a signal of peer productivity, allows us to measure the intensity of peer pressure. Consequently, we are able to investigate, not only the average effect of peer pressure, but also detect non-linearities in the relationship between peer pressure intensity and productivity. Nonlinearities can result from diminishing or increasing returns to peer pressure. Nonlinearities are also predicted by theories of self-assessment developed in social psychology. These theories raise the possibility that providing workers feedback on their individual level of competence can have both positive and negative effects on productivity. For example, Deci (1975) notes that a person's intrinsic motivation will increase with feelings of competence, and decrease with feelings of incompetence. In the case of peer pressure, workers can infer their own level of competence from signals about the productivity of other workers. A low signal may increase the feelings of competence and result in productivity increases, whereas a very high signal may decrease feelings of competence and result in productivity decreases. This effect is potentially important when productivity is primarily driven by intrinsic motivation, such as under a fixed wage payment system. 
Finally, we consider interactions between gender and peer pressure. We systematically analyze the effects of peer pressure intensity on the productivity of women and men, working under differing levels of extrinsic and intrinsic motivation. Gender gaps in earnings and the lower promotion rates of women within the firm are well documented. ${ }^{2}$ Such differences have traditionally been attributed to easily observable differences in abilities, or difficult-to-measure employer discrimination. An alternative explanation is that men and women may differ in terms of unobservable abilities which are correlated with social position attainment within the firm, such as their behavior under competitive pressures. Recently, Gneezy and Rustichini (2004) found that within an environment, absent of extrinsic motivation, peer pressure significantly affected the performance of male children while having no affect on the performance of female children. Our experiment allows us to investigate whether these results are robust to changes in the motivational environment and to characterize the interactions between peer pressure, incentives, and gender in the workplace.

Our results are as follows. First, in the absence of peer pressure, switching from a fixed wage to a piece rate increases productivity by $30 \%$ among women and $23.5 \%$ among men. The increase is statistically significant for women but not for men. Second, men seem to react more to peer pressure than do women. When workers are paid a fixed wage, an exogenous increase in peer pressure has a significant impact on the productivity of men but not of women. The impact of peer pressure intensity on the productivity of men is found to be non-linear. In particular, there exists a threshold level of peer pressure below which an increase in peer pressure significantly increases productivity, and above which an increase in peer pressure significantly reduces productivity. We argue that this inverted $U$ shape pattern is consistent with theories of self-assessment which predict that too high a signal about the productivity of other workers can foster demoralizing behavior and reduce intrinsic motivation. Finally, we find no evidence that peer pressure affects the productivity of men or women when workers are paid piece rates.

The rest of the paper is organized as follows. The next section presents the experimental design. Section 3 presents a simple theoretical model of peer pressure and incentives. In section 4 , we present and analyze the data. Section 5 presents our conclusions.

\footnotetext{
${ }^{2}$ In the Harvard Business Review, it was reported that in 2003 women made up more than half the managerial and professional labour pool, but held only one percent of chief executive positions in Fortune 500 companies.
} 


\section{Experimental design}

The experiment took place at the laboratory of the Center for Interuniversity Research and Analysis on Organizations (CIRANO). Participants were recruited via the CIRANO's list of participants to previous experiments. The email invitation solicited participants for a session of work lasting 40 minutes. The invitation email also informed participants that they would receive a $10 \$$ show up fee on the day of the work session. They were also informed that, depending on the quality of their work, they would receive a payment for their work which would be mailed to them in the week following their participation. More details about the quality control were given before the beginning of each work session.

The experiment consists of a 2 by 2 design of four treatments. In each treatment, instructions explaining the task and payment system were distributed and read out loud. The task consisted of typing scorecards of professional golfers in a database. Workers were informed that the data entered would be used by university researchers to conduct their own research. Scorecards were obtained from the web site of the Professional Golfers Association of America (www.pgatour.com). All scorecards consisted of four rounds of golf for a given golfer, with each round consisting of 18 holes. $^{3}$

Each participant was assigned to a work desk consisting of a computer and a booklet containing the scorecards which had to be entered in a database. Each page of a booklet contained the scorecard of a professional golfer. Figure 2 presents a sample scorecard. Each golfer is identified by an ID number located in the top left corner of the page. Each column contains the scores on each of the 18 holes in a round of golf. A small presentation showed to workers how the data would be entered in the database. In order to facilitate data entry, the entry screen mimicked the scorecards. Figure 3 presents a snapshot of the entry screen. As we can see, the golfer ID number and rounds of golf are positioned in a similar way on both the scorecards and the entry screen. The entry screen contained two additional components not present on the scorecard sheets. First, the cell "\# Rnd de départ" contained the number of rounds of golf present in the database at the beginning of the work session. This number remained fixed throughout the work session. As will be made clear below, this was the critical cell used to

\footnotetext{
${ }^{3}$ We did not use the scorecards for golfers who failed to make the cut since this would imply that only two rounds of golf would be observed.
} 
induce peer pressure. Workers could keep track of their own productivity by looking at the cell "Votre \# Rnd entrées" which contained the number of rounds of gold they have entered since the beginning of the work session. After workers finished entering a scorecard, the entry screen would be refreshed and the number of rounds of golf entered ("Votre \# Rnd entrées") would be incremented by 4 .

The four treatments capture different work environments which differed according to the payment system and the amount of peer pressure. Participants in a treatment were given information about their work environment. They were then unaware that workers in other sessions worked in a different environment. Because the productivity data from the treatments without peer pressure are used to induce peer pressure, we conducted the treatments without peer pressure first. In treatment FW-NoPP (fixed wage payment and no peer pressure), participants received a fixed payment of $10 \$$ for their work (on top of the $10 \$$ show-up fee) and received no information about the productivity of other participants. In treatment PR-NoPP (piece-rate payment and no peer pressure), participants were paid $0.1 \$$ for each round of golf entered and received no information about the productivity of other participants. In both treatments, each participant started entering data in a new database. As a result, the cell "\# Rnd de départ" containing the number of rounds of golf in the database at the beginning of the work session was set to 0 for all participants.

In the other two treatments, FW-PP (fixed wage payment and peer pressure) and PR-PP (piece-rate payment and no peer pressure), are similar except that peer pressure was added. Each participant in the FW-PP treatment had to start entering data in a database randomly chosen from the pool of participants in the FW-NoPP treatment conducted earlier. As a result, the cell "\# Rnd de départ" contained the number of rounds of golf entered by another participant paid under a fixed wage system. Because the productivity of participants in the FW-NoPP varied, the number appearing in the cell "\# Rnd de départ" varied across workers in the FW-PP treatment. This insured that workers in the FW-PP treatment were exposed to different intensities of peer pressure. In a similar way, peer pressure was introduced in the piece rate payment system by having participants in the PR-PP treatment enter data in a database of a randomly chosen participant in the PR-NoPP treatment.

A description of the quality control then followed. The quality control was the same for all treatments and consisted of randomly drawing $20 \%$ of the rounds entered by a worker and 
counting the number of rounds entered with mistakes. If less than $20 \%$ of the rounds selected for the control contained mistakes, the worker received his payment for the work done. If more than $20 \%$ of the rounds selected for the control contained mistakes, the worker received no payment for the work done. All workers received by mail a summary of the quality control procedure and, depending on the results of the control, a payment for their work.

After exactly 40 minutes of work, a bell rang signaling the end of the work session. Participants collected their $10 \$$ show-up fee before leaving the room. In the week following the experiment, the quality control check was performed, and checks and a description of the results of the quality control were mailed to the participants.

\section{Model}

In this section we develop a theoretical model that describes tractable model. For the instant we ignore quality decisions on the part of the worker. We consider worker utility to be separable in money and effort; ie, $U(W, E)=W-C(E)$. The theoretical concept of intrinsic motivation implies effort is supplied independently of monetary rewards; workers will supply effort under fixed wages. To capture these ideas in an empirically tractable manner, we specify a cost of effort function of the form

(1) $\quad C(E)=\frac{\kappa_{i}}{\psi} E^{\psi}-\eta_{i} E, \quad \kappa_{i}>0, \psi>0, \eta_{i}>0$.

Notice, since the marginal cost of effort is negative at zero effort, individuals will supply positive effort levels under a fixed wage. We interpret $\eta_{i}$ to be then intrinsic motivation parameter in our model. Both $\eta$ and $\kappa$ are subscripted with $i$ to denote that they can vary across workers.

Since little affects productivity beyond worker actions, we simply take output to be worker effort; ie, $Y=E$. Earnings are given by

(2) $W= \begin{cases}r Y & \text { ifpaymentbypiecerates } \\ \omega & \text { ifpaymentby fixedwages. }\end{cases}$

Optimal output choice under piece rates is given by

(3) $y^{p r}=e^{p r}=\frac{(r+\eta)^{\gamma}}{\kappa}$. 
Under fixed wages, optimal effort is given by

(4) $y^{f w}=e^{f w}=\frac{\eta}{\kappa}^{\gamma}$.

Notice that $\eta>0$ is a necessary condition for positive output under fixed wages. Since extrinsic incentives are equal to zero, a worker only supplies positive effort if he is intrinsically motivated to do so.

The logarithm of output is then

$$
\begin{aligned}
& \ln y^{p r}=\gamma \ln (r+\eta)-\gamma \ln \kappa \\
& \ln y^{f w}=\gamma \ln \eta-\gamma \ln \kappa .
\end{aligned}
$$

Since there is no inherent risk in typing golf scores, the distribution of output is caused solely by the distributions of $\eta$ and $\kappa$ in the sample of workers. We specify

$$
\begin{aligned}
& \eta_{i}=e^{X_{i} \beta+\lambda P P_{i}+v_{i}} \\
& \kappa_{i}=e^{X_{i} \delta+\epsilon_{i}}
\end{aligned}
$$

where $P P_{i}$ denotes the level of peer pressure and $v$ and $\epsilon$ are random variables.

Because peer pressure affects intrinsic motivation, the impact of peer pressure on productivity directly depends on the strength of the relationship between intrinsic motivation and productivity. We next show that the effect of intrinsic motivation on productivity is crowded out by the use of extrinsic motivation. To proceed, let the cost of effort function be increasing and convex (i.e. $\gamma>0$ ). Then, from (3) it follows that changes in intrinsic motivation affect productivity according to the following simple formula

$$
\frac{\partial \ln y^{p r}}{\partial \eta}=\frac{\gamma}{r+\eta}>0
$$

It follows directly from the above equation that the effects of changes in intrinsic motivation on productivity diminish with the level of extrinsic motivation

(7) $\frac{\partial}{\partial r}\left[\frac{\partial \ln y^{p r}}{\partial \eta}\right]=-\frac{\gamma}{(r+\eta)^{2}}<0$

This leads to the easily testable prediction that the effects of peer pressure on productivity through changes in intrinsic motivation are greater in magnitude when workers are paid fixed 
wages as opposed to piece-rates. Intuitively, workers exert more effort in response to increases in extrinsic motivation. By increasing their effort, workers also increase their marginal cost of effort, making it more costly for them to respond to peer pressure. This is one motivation for the conjecture that extrinsic motivation may crowd out intrinsic motivation.

\section{Results}

\subsection{Aggregate results}

Table 1 presents descriptive statistics of productivity, quality of work, age and gender for all in our four treatments. Because of our randomized experimental design, the average age of our workers (27.45) and the proportions of women and men are similar across treatments. We find that workers entered an average of 85.33 rounds when paid a fixed wage without peer pressure. Because workers knew they were hired for a single day of work, we rule out the possibility that this level of productivity reflects concerns for future employment. As a result, we interpret productivity in the fixed wage treatment without peer pressure as evidence of considerable intrinsic motivation. Surprisingly, we find that the average productivity of workers paid a fixed wage and exposed to peer pressure is 82.20 rounds of golf, slightly lower than the average productivity of workers without peer pressure.

The incentive effects of using piece-rates are present both with and without peer-pressure. We find that workers entered an average of 107.18 rounds without peer pressure, an increase of $25.6 \%$ relative to the fixed wage treatment without peer pressure. Similarly, an average of 114.05 rounds were entered in the piece-rate treatment with peer pressure, an increase of $38.7 \%$ relative to the average productivity in the fixed wage treatment with peer pressure. ${ }^{4}$

Figure 1 presents the distributions of the number of rounds entered containing mistakes for the four treatments. We find similar distributions of mistakes with and without peer pressure, given a payment system. Across payment systems, workers are more likely to make a mistake when paid a piece-rate rather than a fixed wage. This finding is consistent with existing findings that workers being paid piece rates tend to tradeoff quality and productivity (e.g. Paarsch

\footnotetext{
${ }^{4}$ These results are in line with existing empirical evidence from observational studies and field experiments which find that productivity increases when workers are paid piece-rates rather than fixed wages (Lazear (2000), Paarsch and Shearer (2000), Shearer (2004))
} 
and Shearer, 2000).

\subsection{Regression results}

\section{Productivity}

We use the natural logarithm of productivity $p_{i}$ of worker $i$ as our dependent variable. We will perform our analysis separately for gross and net productivity. Gross productivity is defined as the total number of rounds of golf entered $\left(p_{i}=y_{g}+y_{b}\right)$, and thus does not control for the number of rounds entered with mistakes. An obvious drawback of this measure is that rounds entered with error $y_{b}$ do not represent real productive work. Net productivity is simply defined as the total number of rounds correctly entered $y_{g}$.

For whichever measure of $p_{i}$ used, we use the following model of productivity

$$
\text { (8) } \begin{aligned}
\ln \left(p_{i}\right)= & \beta_{0}+\beta_{1} P R_{i}+\beta_{2} F W_{i} \times P P_{i}+\beta_{3} F W_{i} \times P P_{i}^{2} \\
& +\beta_{4} P R_{i} \times P P_{i}+\beta_{5} P R_{i} \times P P_{i}^{2}+\beta_{6} A g e_{i}+\varepsilon_{i}
\end{aligned}
$$

where $F W_{i}$ and $P R_{i}$ are binary variables respectively taking a value of 1 when worker $i$ is paid a fixed wage or a piece-rate, and 0 otherwise. $P P_{i}$ denotes peer pressure measured in numbers of rounds of golf entered (divided by 10). A quadratic term in $P P_{i}$ is added to capture possible non-linearities between peer pressure and productivity. $A g e_{i}$ denotes de age of the worker, and $\varepsilon_{i}$ denotes unobserved heterogeneity. When there is no peer pressure $\left(P P_{i}=0\right)$, the difference in productivity between a fixed wage payment and a piece rate is captured by $\beta_{1}$. The effect of peer pressure on productivity when workers are paid a fixed wage is captured by $\left(\beta_{2}, \beta_{3}\right)$, the parameters of the interaction between $F W$ and the peer pressure variables. Similarly, the effect of peer pressure on productivity when workers are paid a piece rate treatment is captured by $\left(\beta_{4}, \beta_{5}\right)$, the parameters of the interaction between $P R$ and the peer pressure variables. Finally, we assume that the distribution of $\varepsilon_{i}$ has a median of zero, conditional on the exogenous variables in model. This conditional median restriction implies that the estimated values of $\left(\beta_{0}, \beta_{1}, \ldots, \beta_{6}\right)$ represent estimated marginal changes of the conditional median of $\ln \left(p_{i}\right)$ for the corresponding control variables. Because the conditional median restriction on $\varepsilon_{i}$ is weaker 
than a conditional mean assumption, median regressions are known as robust estimation techniques (see Koenker (2005) for more details).

We estimated equation (8) for men and women workers separately. Results are presented in Table 2 for both gross and net productivity. ${ }^{5}$ In the absence of peer pressure, $P R$ captures the effect of changing the payment from a fixed wage to a piece rate. We find that passing from fixed wage to a piece rate significantly increases the gross and net productivity of women respectively by $30.2 \%$ and $30 \%$. The gross and net productivity of men respectively increases by $23.5 \%$ and $20 \%$, but these increases are not statistically significant. ${ }^{6}$.

When workers are paid a fixed wage, the effect of peer pressure varies between gross and net productivity, and between men and women workers. Peer pressure has no significant impact on net productivity of women paid a fixed wage. On the other hand, peer pressure has a significant impact on net productivity of men paid a fixed wage. In the later case, the relationship between peer pressure intensity and productivity is inverted $U$ shape, attaining a maximum productivity level at a level of pressure of approximately 40 rounds of golf. ${ }^{7}$ The fact that productivity diminishes after peer pressure reaches a certain level is consistent with theories of self-assessment and motivation.

Contrary to the fixe wage case, there is no significant relationship between peer pressure and either gross or net productivity of men and women when workers are paid a piece-rate. This result is consistent with the prediction given in equation (7) which stated that the effect of peer pressure on productivity should be smaller, in absolute terms, when extrinsic motivation is used. Finally, there is a significant negative relationship between productivity and age for both women and men, with an additional year reducing median productivity by approximately $2 \%$.

\footnotetext{
${ }^{5}$ We easily reject the null hypothesis that the regression coefficients are joint similar for men and women in both the gross $(p$-value $=0.0001)$ and net $(p$-value $=0.0000)$ productivity equations, thereby indicating that men and women appear to perform differently in the experiment.

${ }^{6}$ Paarsch and Shearer (2005) find that there are no significant differences in the response of male and female tree planters to a change in the piece-rate.

${ }^{7}$ This number is obtained by maximizing $0.153 \times P P-0.019 P P^{2}$ with respect to $P P$ and solving using the fact that $P P$ measures the number of rounds of golf entered divided by 10.
} 


\section{Quality}

Figure 1 presents the distribution of the number of rounds entered with mistakes in each of the four treatments. We find that, both with and without peer pressure, the proportions of subjects not making any mistakes is higher when workers are paid a fix wage than paid a piece-rate. This pattern is consistent with workers under piece-rate substituting quality for quantity (see e.g. Paarsch and Shearer (2000) for the case of the tree-planting industry).

To investigate systematically the relationship between quality of the work, incentives, and gender, let $N$ be the number of workers in the experiment, and $y_{b i} \in\{0,1, .$.$\} denote the number$ of mistakes of worker $i$, where $i=1,2, \ldots, N$. We assume that $y_{b i}$ follows a negative binomial distribution whose first two moments are assumed to satisfy

$$
\begin{aligned}
\mathbf{E}\left(y_{b i} \mid \mathbf{x}_{i}\right) & =\exp \left(\mathbf{x}_{i}^{\prime} \boldsymbol{\alpha}\right) \\
\mathbf{V}\left(y_{b i} \mid \mathbf{x}_{i}\right) & =\left(1+\theta \exp \left(\mathbf{x}_{i}^{\prime} \boldsymbol{\alpha}\right)\right) \exp \left(\mathbf{x}_{i}^{\prime} \boldsymbol{\alpha}\right)
\end{aligned}
$$

such that $\theta \geq 0$. This parameterization allows the conditional variance to exceed the conditional mean, a phenomena known as overdispersion and which is frequently observed in count data models (see Cameron and Trivedi 1998). A special case is the Poisson distribution (with $\theta=0$ ), characterized by equidispersion (the conditional variance equals the conditional mean). Estimation of $\alpha$ and $\theta$ is done by Maximum Likelihood.

The model was estimated separately for men and women workers. ${ }^{8}$ The last two columns of Table 2 contain the regression results. Looking at men first, we find that those being paid a piece-rate did not make significantly more mistakes that those being paid a fixed wage. This is consistent with the finding that men did not react significantly to the incentives by significantly increasing productivity under the piece-rate (see results on productivity above). We further find a small positive but significant relationship between the number of mistakes and age. Finally, we do not find that peer pressure has any significant effect on quality amongst the men population.

Unlike men, women working under a piece-rate make significantly more mistakes than women working under a piece-rate. Given women have significantly more productive under

\footnotetext{
${ }^{8} \mathrm{~A} \log$-likelihood ratio test easily rejects the null hypothesis that the coefficients in the men and women regressions are the same $\left(\chi_{8}^{2}=29.128, p\right.$-value $\left.=0.0003\right)$.
} 
the piece-rate than the fixed wage (see results on productivity), is thus appears that women traded off quality for quantity when working under the piece-rate. Moreover, contrary to men, there is no significant relationship between age and quality of work. again, we do not find a significant relationship between peer pressure and quality in both payment systems.

\section{Conclusions}

We have presented results from a real effort experiment where the payment system and the intensity of peer pressure were both varied exogenously between workers. Our experimental design allowed us to estimate the effect of peer pressure intensity on the productivity of workers under both fixed wages and piece rates.

Our results contribute to the literature in several ways. First, we found that the effect of peer pressure on productivity depends on the intensity of monetary incentives (extrinsic motivation) and gender. In particular, we found that productivity of women is not significantly affected by peer pressure when paid either a fixed wage or a piece-rate. This suggests that the findings of Gneezy and Rustichini (2000), whereby females did not react to peer pressure, generalize beyond environments without extrinsic motivation.

We also found a significant non-linear relationship between productivity of men paid a fixed wage and peer pressure intensity: productivity significantly increased with the intensity of peer pressure up to a critical level of peer pressure, and significantly decreases beyond this critical level. We have argued that this non-linear relationship is consistent with theories of self-assessment according to which peer pressure can increase or decreases a workers feelings of competence, and thus affect intrinsic motivation and productivity. More generally, this suggests that peer pressure has a limited range of effectiveness as an incentive-policy tool.

Our results also demonstrate the usefulness of experimental methods for analysing motivational models by generating random variation in (unobservable) forcing variables. Intrinsic motivation and peer pressure are difficult to measure in real firms. The work of Falk and Ichino (2006) as well as that of Gneezy and Rustichini demonstrated that it can be generated in laboratory (like) environments. Here, we have generated exogenous variation in peer pressure, allowing us to uncover nonlinearities in its effect on productivity. The random matching of workers ensures that every worker has a positive probability of being matched with a worker 
of higher or lower ability.

The different reactions between male and female workers also provides an alternative explanation for historical data showing a tendency for women to be paid piece rates. Goldin (198?) has argued that piece rates are useful incentive mechanisms for women since they traditionally spent less time in the work force and therefore responded less to the chance of future promotions. Our results suggest that piece rates may be popular because women react less to the implicit competition provided by peer pressure.

Finally, our results also have implications for the design of workplace practices. They suggest that peer pressure can successfully increase productivity when productivity is primarily driven by intrinsic motivation such as in a fixed wage environment, although this may work better for male workers. Historical data demonstrates that females are more likely to be paid piece rates than are males. Goldin (1986) has argued that this was efficient: females traditionally spent less time in the labour market and, hence, could not be motivated by the opportunity of future promotions. Our results suggest that women may also react less to the intrinsic motivation in fixed wages. 


\begin{tabular}{lccccc}
\hline \hline & & & & & \\
RW-NoPP & PR-NoPP & FW-PP & PR-PP & All workers \\
& 85.333 & 107.179 & 82.200 & 114.051 & 96.875 \\
Rounds with mistakes & $(37.902)$ & $(36.982)$ & $(41.567)$ & $(42.191)$ & $(41.645)$ \\
& 2.404 & 5.436 & 1.725 & 3.333 & 3.200 \\
Age & $(5.296)$ & $(12.711)$ & $(2.241)$ & $(4.163)$ & $(7.291)$ \\
& 27.428 & 27.307 & 27.95 & 27.102 & 27.450 \\
Female & $(7.444)$ & $(8.189)$ & $(8.317)$ & $(6.832)$ & $(7.651)$ \\
& 0.523 & 0.436 & 0.525 & 0.513 & 0.500 \\
Earnings \$ & $(0.505)$ & $(0.502)$ & $(0.505)$ & $(0.506)$ & $(0.501)$ \\
& 10 & 10.71 & 10 & 11.40 & 10.34 \\
Number of workers & - & $(3.698)$ & - & $(4.219)$ & $(2.342)$ \\
& 42 & 39 & 40 & 39 & 160 \\
\hline \hline
\end{tabular}

Table 1: Descriptive statistics for the four treatments: fixed wage with (FW-PP) and without (FW-NoPP) peer pressure, and piece-rate wage with (PR-PP) and without (PR-NoPP) peer pressure. 


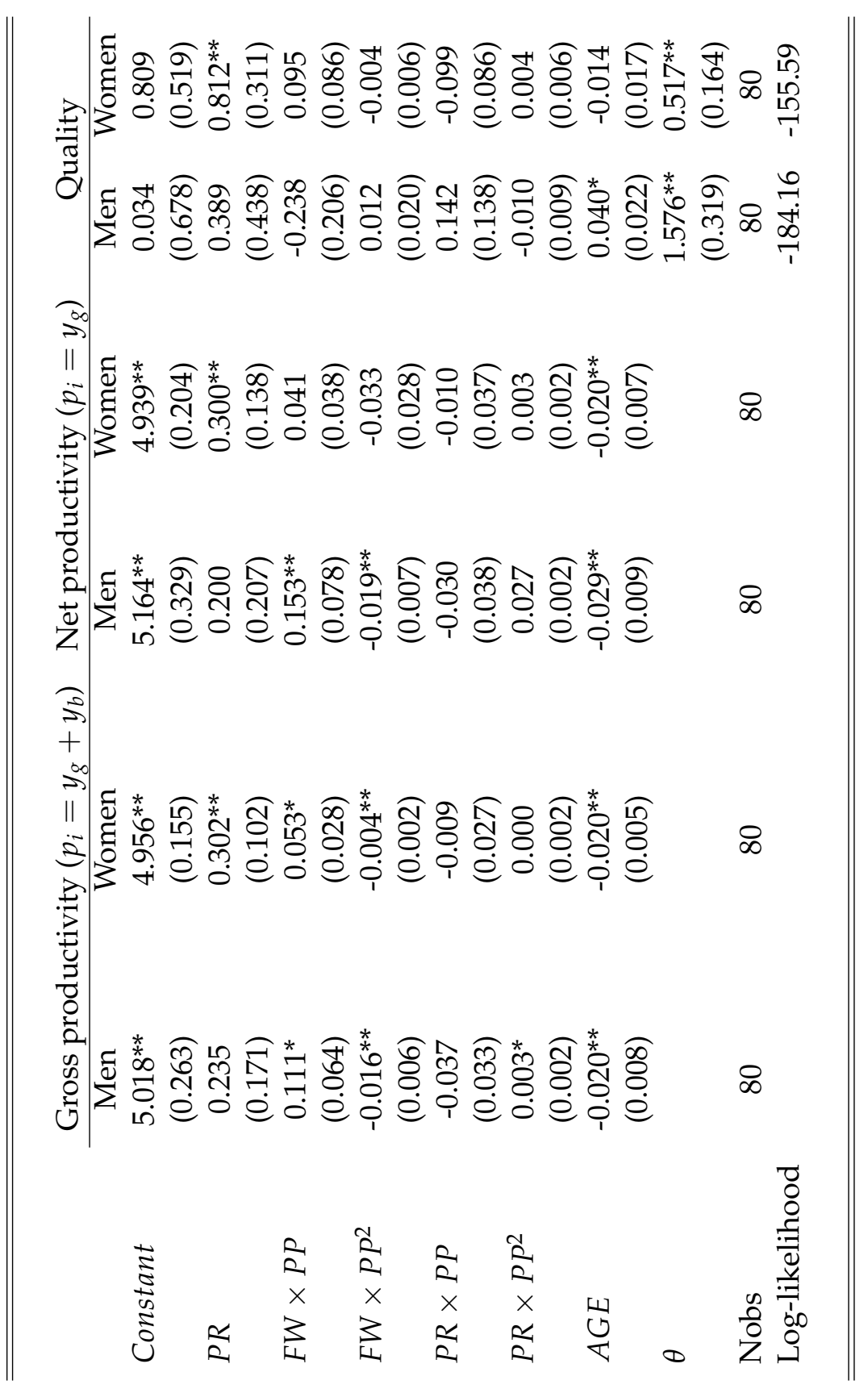

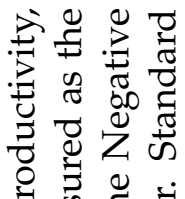

है के

क छ 战䒕䒕

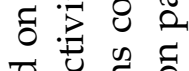
चु पै के

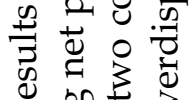
0 - 50 跑䨌

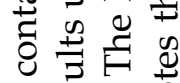
क क ర) 능 द्वे

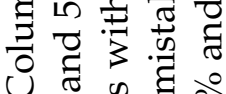
항 용

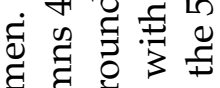
उ릉 항 可 U 议 要

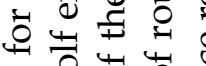
年 당 政 so 5 है 政

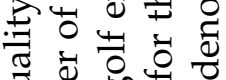

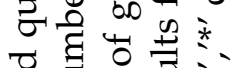
돌 居要 늘

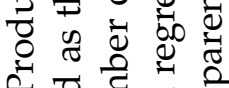

证 i

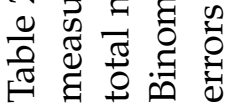




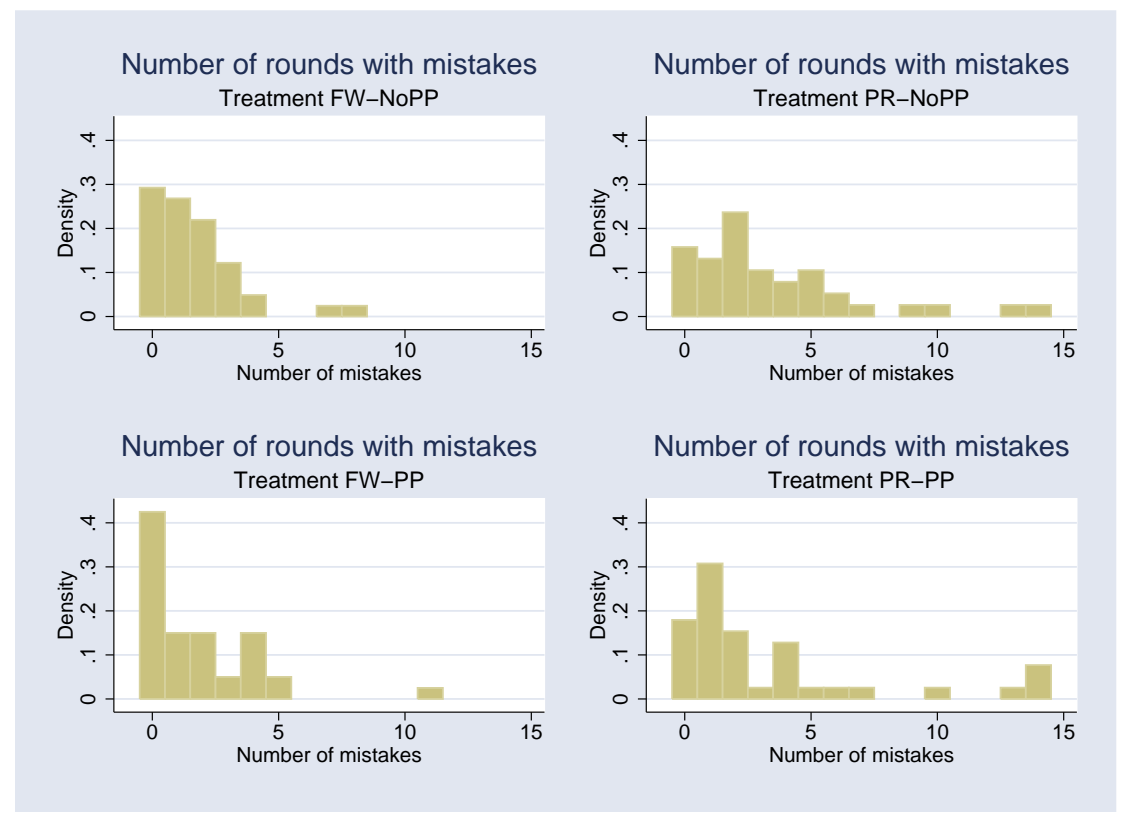

Figure 1: Number of rounds of golf entered with mistakes across the four treatments. 


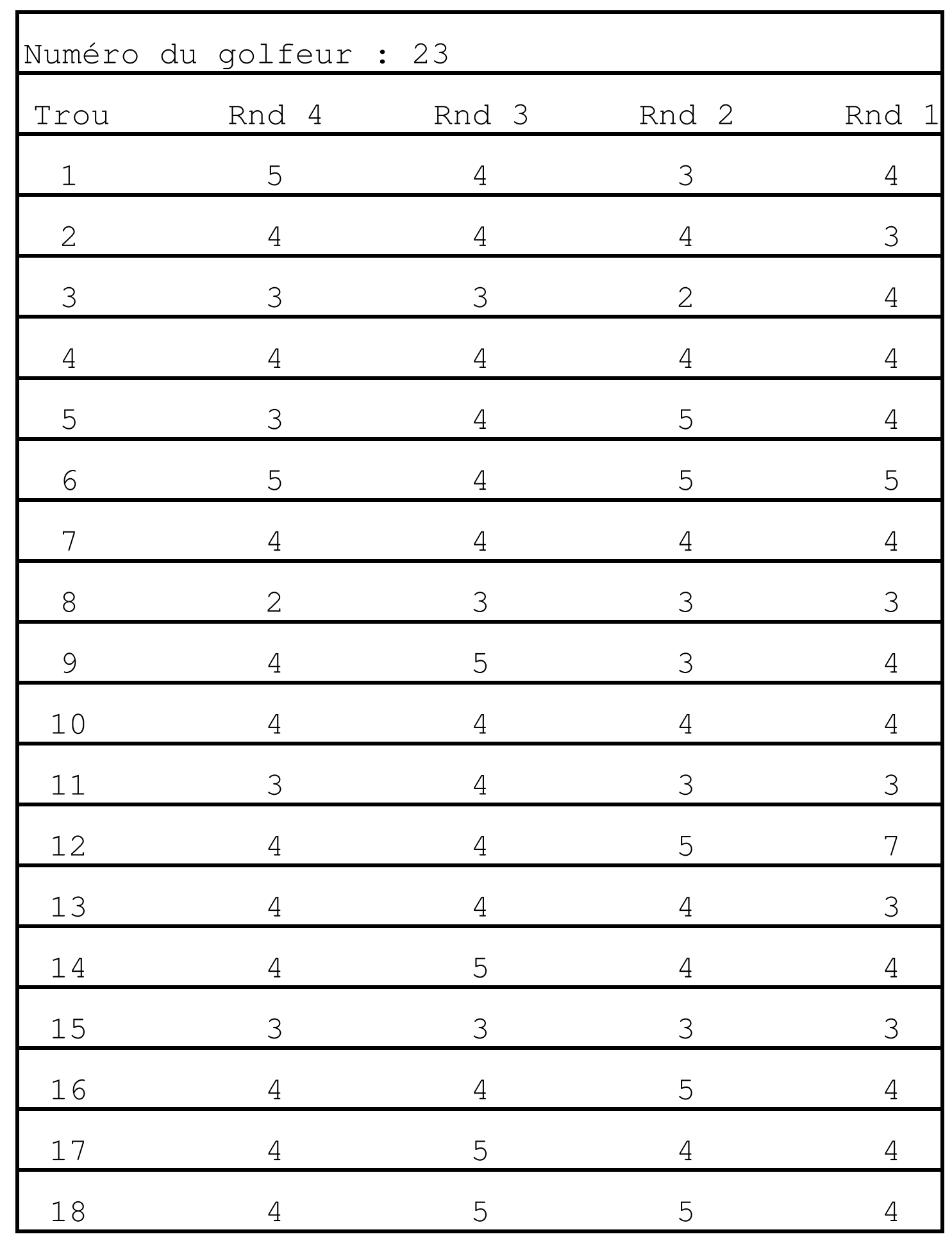

Figure 2: Sample scorecard taken from a worker's booklet. 


\begin{tabular}{|c|c|c|c|c|c|c|}
\hline \multicolumn{2}{|c|}{ Rnd de départ: } & \multirow{2}{*}{93} & \multicolumn{4}{|c|}{ Votre \# Rnd entrées : 32} \\
\hline \multicolumn{6}{|c|}{ Numéro du golfeur $\longdiv { 9 }$} & \\
\hline Hole & Rnd 4 & & Rnd 3 & Rnd 2 & Rnd & \\
\hline 1 & $\sqrt{4}$ & & $\sqrt{4}$ & $\sqrt{3}$ & $\sqrt{4}$ & \\
\hline 2 & $\overline{3}$ & & $\overline{5}$ & $\overline{4}$ & $\overline{4}$ & \\
\hline 3 & 2 & & $\overline{4}$ & $\overline{3}$ & $\sqrt{3}$ & \\
\hline 4 & $\overline{3}$ & & $\overline{3}$ & $\overline{44}$ & $\overline{14}$ & \\
\hline 5 & 5 & & 5 & 4 & 4 & \\
\hline 6 & 3 & & $\overline{4}$ & $\overline{5}$ & $\overline{14}$ & \\
\hline 7 & $\overline{5}$ & & $\overline{4}$ & $\overline{4}$ & $\overline{14}$ & \\
\hline 8 & 3 & & 4 & 3 & $\sqrt{4}$ & \\
\hline 9 & 4 & & 4 & 4 & $\sqrt{4}$ & \\
\hline 10 & 3 & & 5 & $\overline{6}$ & $\sqrt{3}$ & \\
\hline 11 & 3 & & $\overline{3}$ & $\overline{3}$ & $\overline{3}$ & \\
\hline 12 & 5 & & 4 & 4 & $\sqrt{5}$ & \\
\hline 13 & $\overline{4}$ & & $\overline{4}$ & $\overline{4}$ & $\overline{4}$ & \\
\hline 14 & 3 & & 4 & 4 & 4 & \\
\hline 15 & 2 & & 2 & 3 & 3 & \\
\hline 16 & 3 & & 4 & 5 & 14 & \\
\hline 17 & 4 & & 15 & 4 & 15 & \\
\hline 18 & 4 & & 6 & 4 & 14 & \\
\hline
\end{tabular}

Figure 3: Snapshot of the data entry screen. 


\section{References}

DECI, E. (1975): Intrinsic Motivation. Plenum Press, New-York.

Frey, B., AND R. Jegen (2001): “Motivation Crowding Theory," Journal of Economic Surveys, 15.

GneEZy, U., AND A. Rustichini (2004): “Gender and Competition at a Young Age,” American Economic Review Papers and Proceedings, 94, 377-381.

Kandel, E., And E. LAzeAR (1992): "Peer Pressure and Partnerships," Journal of Political Economy, 100.

KoenKer, R. (2005): Quantile Regression. Cambridge University Press, Cambridge, U.K.

LaZeAr, E. (2000): "Performance Pay and Productivity," American Economic Review, 90, 13461361.

PaArsch, H., ANd B. Shearer (2000): “Piece Rates, Fixed Wages and Incentive Effects: Evidence from Payroll Data," International Economic Review, 41, 59-92.

SheArer, B. (2004): "Piece Rates, Fixed Wages and Incentives: Evidence from a Field Experiment," Review of Economic Studies, 71, 513-534. 